\title{
Carmen Boustani, Effets du féminin, variations narratives francophones
}

\section{Simona Rossi}

\section{(2) OpenEdition}

1 Journals

\section{Edizione digitale}

URL: http://journals.openedition.org/studifrancesi/36776

DOI: 10.4000/studifrancesi.36776

ISSN: 2421-5856

\section{Editore}

Rosenberg \& Sellier

\section{Edizione cartacea}

Data di pubblicazione: 1 juillet 2005

Paginazione: 205

ISSN: 0039-2944

\section{Notizia bibliografica digitale}

Simona Rossi, «Carmen Boustani, Effets du féminin, variations narratives francophones», Studi Francesi

[Online], 145 (XLIX | I) | 2005, online dal 30 novembre 2015, consultato il 18 avril 2021. URL: http:// journals.openedition.org/studifrancesi/36776 ; DOI: https://doi.org/10.4000/studifrancesi.36776

Questo documento è stato generato automaticamente il 18 avril 2021.

\section{(c) $(1) \&$}

Studi Francesi è distribuita con Licenza Creative Commons Attribuzione - Non commerciale - Non opere derivate 4.0 Internazionale. 


\title{
Carmen Boustani, Effets du féminin, variations narratives francophones
}

\author{
Simona Rossi
}

\section{NOTIZIA}

CARMEN BOUSTANI, Effets du féminin, variations narratives francophones, Paris, Karthala, 2003, pp. 239.

1 Si può parlare di scrittura neutra, asessuata? È questo il primo quesito che si pone Carmen Boustani, autrice di questo interessante volume sulla scrittura femminile. La sua risposta è no, poiché secondo le sue teorie nell'atto di scrivere è necessariamente incluso le paramètre du rapport masculin/féminin (p. 9). Ciò che l'opera mette in luce, quindi, non è tanto la scrittura du féminin come spazio (privilegiato) riservato alle donne, quanto luogo di creazione fondamentale del rapporto tra i due sessi, che può trovarsi sia in testi scritti da individui di sesso femminile che maschile. Qui l'autrice sceglie di limitarsi a scrittrici donne di lingua francese, come Georges Sand, Abla Farhoud, Maryse Condé, Nicole Brossard e molte altre, di cui considera le opere. Estremamente diverse tra loro per genere (romanzo, novella, lettera), stile, epoca e contenuto, esse riflettono molto bene il rapporto indivisibile tra natura, sesso e cultura. Carmen Boustani lo dimostra attraverso la lucida analisi di un vasto immaginario femminile che percorre tutte le tappe dell'elaborazione $d u$ féminin, dall'ultimo, titubante tributo alla sovranità maschile ai primi passi verso l'autonomia, dall'errata esigenza d'imitazione fino al ri-trovato equilibrio della donna di oggi, più in armonia con se stessa e con i suoi desideri.

Les effets du féminin sono dunque uno studio particolareggiato delle caratteristiche della "femminilità di scrittura", le quali emergono attraverso l'attenzione e l'insistenza dell'autrice sui processi linguistici e di scrittura. È così che si scopre che le féminin è spesso caratterizzato da una incredibile mescolanza tra testo e vita reale, tra voce e scrittura, da una certa "corporeità" della parola, che non può trascendere dalla 
sensazione, e da una libertà linguistica del tutto particolare, la quale non mira, come si potrebbe pensare, alla creazione di una lingua a misura di donna, ma di uno spazio femminile comune ai due sessi in grado di differenziare le féminin senza marginalizzarlo. Queste sono solo alcune delle interessanti chiavi di lettura offerte dal volume: il lettore che scorre le sue pagine compie una sorta di viaggio, attraverso il tempo e lo spazio, nel coinvolgente mondo du féminin. Dal Maghreb al Québec, dal Belgio all'Africa nera, dall'Esagono alle Antille, voci di donne illustrano, infatti, facendosi eco le une con le altre, nuove esigenze di scrittura poetica (Andrée Chedid), di una narrativa trasgressiva, capace di rompere gli argini della tradizione (Nicole Brossard), di una forte ricerca d'identità (Assia Djebar e Abla Farhoud) e di un febbrile istinto di rivendicazione contro l'autorità patriarcale (Mariana Bâ). Sensibile omaggio al significato più recondito della femminilità che entra a far parte della scrittura $e$ dettagliato studio letterario, il volume merita senza dubbio grande attenzione. 